\title{
Resource implications for a population-based colorectal cancer screening program in Canada: A study of the impact on colonoscopy capacity and costs in London, Ontario
}

\author{
Agatha Lau MD MSc, James C Gregor MD FRCPC
}

\begin{abstract}
A Lau, JC Gregor. Resource implications for a populationbased colorectal cancer screening program in Canada: A study of the impact on colonoscopy capacity and costs in London, Ontario. Can J Gastroenterol 2007;21(6):371-377.
\end{abstract}

OBJECTIVE: Cancer Care Ontario has recommended a populationbased colorectal cancer (CRC) screening program using fecal occult blood testing. Patients who test positive should undergo further investigation, preferably colonoscopy. So far, no studies have been performed to quantify the costs or demands on the health care system at the community level. The number of consultations, colonoscopies and polypectomies, and the corresponding direct medical costs generated by the CRC screening program, between 2006 and 2015 in London, Ontario, were estimated using a decision analysis model in comparison with the population health model.

METHODS: A faxed survey study was conducted to examine the current CRC screening practice among family physicians in London. Data from the survey and randomized studies were applied to a decision analysis model, which simulated the steps involved in population-based biennial and annual CRC screening between 2006 and 2015. The number of consultations, colonoscopies and polypectomies, and their associated costs were calculated.

RESULTS: For a cohort population of 140,000, between 50 and 74 years of age, in 2006 to 2015, it is estimated that an average of 412 consultations, 463 colonoscopies and 174 polypectomies will be performed per 100,000 screen eligible population per year in biennial screening, and double in annual screening, reflecting an average of $8.7 \%$ or $17.6 \%$ increase annually in outpatient colonoscopies, respectively, compared with 2003 . A mean of $\$ 285,000$ or $\$ 562,000$ per year would be required to support the extra consultation and endoscopic procedures generated by the biennial or annual screening. CONCLUSION: Population-based fecal occult blood testing screening for CRC appears to be a manageable strategy if a modest increase in endoscopic resources is allocated.

Key Words: Colonoscopy; Colorectal cancer screening; Cost study; Resource
Les répercussions sur les ressources d'un programme de dépistage du cancer colorectal en population au Canada : Une étude des répercussions sur la capacité et les coûts de la coloscopie à London, en Ontario

OBJECTIF : Action Cancer Ontario a recommandé la tenue d'un pro-
gramme de dépistage du cancer colorectal (CCR) en population au
moyen d'une recherche de sang occulte dans les selles (RSOS). Les
patients positifs doivent subir un autre examen, de préférence une colo-
scopie. Jusqu'à présent, aucune étude n'a porté sur la quantification des
coûts ou des exigences sur le système de santé communautaire. On a
estimé le nombre de consultations, de coloscopies et de polypectomies et
les coûts médicaux directs correspondants découlant du programme de
dépistage du CCR, entre 2006 et 2015 à London, en Ontario, au moyen
d'un modèle d'analyse décisionnel par rapport à un modèle de santé de la
population. MÉTHODOLOGIE : On a procédé à une enquête par sondage télécopié pour examiner les pratiques courantes de dépistage du CCR des médecins de famille de London. On a appliqué les données tirées de l'enquête et d'études aléatoires à un modèle d'analyse décisionnelle qui simulait les étapes d'un dépistage annuel et biennal du CCR en population entre 2006 et 2015. On a calculé le nombre de consultations, de coloscopies et de polypectomies et les coûts s'y rapportant.

RÉSULTATS : Pour une cohorte de 140000 habitants de 50 à 74 ans entre 2006 et 2015, on estime que 412 consultations, 463 coloscopies 174 polypectomies seront effectuées pour 100000 habitants admissibles au dépistage par année dans le cadre du dépistage biennal, et le double dans le cadre du dépistage annuel, reflétant une augmentation annuelle moyenne de $8,7 \%$ à 17,6 \% des coloscopies ambulatoires, respectivement, par rapport à 2003. Il faudrait une moyenne de 285000 à 562000 \$ par année pour financer les consultations et les endoscopies supplémentaires qu'exigerait le dépistage biennal ou annuel.

CONCLUSION : La recherche de sang occulte dans les selles en population pour dépister le CCR semble être une stratégie raisonnable si on lui accorde une modeste augmentation des ressources endoscopiques.
$\mathrm{T}$

he incidence of and mortality rates for colorectal cancer (CRC) in Canada are among the highest in the world. According to "Canadian Cancer Statistics 2006" (1), CRC is the third most common cancer in both sexes and the second leading cause of cancer-related deaths in both sexes after lung cancer. There were approximately 20,000 new cases and 8500 deaths from CRC in Canada in 2006.
Multiple randomized controlled trials (2-4) have shown that early detection and treatment of CRC have a significant impact on survival rates. They also demonstrated the efficacy of screening using the fecal occult blood test (FOBT) which decreased the mortality rate of CRC by $15 \%$ to $33 \%$ in a targeted population of 50- to 74-year-olds. These findings were strongly supported by Health Canada's National Committee

Department of Internal Medicine, London Health Sciences Centre, University of Western Ontario, London, Ontario

Correspondence: Dr Agatha Lau, Division of Gastroenterology, Room E2-314, Victoria Hospital, London Health Sciences Centre,

800 Commissioners Road East, London, Ontario N62 4G5. Telephone 519-667-6843, fax 519-667-6620, e-mail alau24@uwo.ca

Received for publication April 20, 2006. Accepted September 5, 2006 
on Colorectal Cancer Screening (5). In 2001, the Canadian Task Force on Preventive Health Care (6) upgraded the FOBT to an 'A' recommendation for screening CRC annually or biennially in the population older than 50 years of age. However, to date, there are no national organized screening programs for CRC in Canada. In Ontario, a recent study (7) showed that approximately only $20 \%$ of Ontarians, 50 to 59 years of age, had any bowel investigations between 1995 and 2000, most of which were not for screening. As a result, different cancer associations endeavoured to develop a more effective nationwide CRC screening program. According to the "Cancer 2020 Background Report" (8), if the population-based CRC screening program could reach $90 \%$ of the target population, an estimated 6000 deaths from CRC could be prevented by 2030.

Individuals with a positive FOBT should undergo further evaluation to investigate the source of bleeding. Current guidelines suggest either colonoscopy or flexible sigmoidoscopy combined with air contrast barium enema $(5,9,10)$. A costeffective analysis showed that colonoscopy is the most costeffective and sensitive modality in detecting advanced adenomas compared with flexible sigmoidoscopy and/or air contrast barium enema and virtual colonoscopy (11).

With the implementation of population-based CRC screening, together with the aging population in Canada, the number of follow-up colonoscopies required after a positive FOBT will be expected to rise dramatically. The estimated rise in the number of colonoscopies for each province has been calculated in the population health model (POHEM) (12). However, it was not calculated for individual cities or counties. In the present study, our goal was to use the city of London, Ontario, as a model to investigate the current practice of CRC screening and colonoscopy capacity in the community, as well as the estimated increased demand in gastrointestinal consultations, colonoscopies and polypectomies, and the corresponding direct medical cost generated from the population-based CRC screening between 2006 and 2015.

\section{METHODS}

The goal of the present study was to estimate the number of consultations and endoscopic procedures, and the corresponding direct medical cost generated by the population-based CRC screening in London. Instead of dividing the national cost, as calculated by the POHEM model in 2003 (12), according to the population in London, a realistic approach as close to the current situation as possible was attempted by taking into account some important local factors that may affect the final calculation, such as the projected population eligible for screening during the 10-year study period, the percentage of the population that can access the screening program (ie, people who have family physicians [FPs]) and the current practice of CRC screening among FPs in London, specifically the use of the FOBT. Therefore, population projection data were obtained from the Department of Planning and Development in London. An FP survey was designed to examine their current practice in CRC screening. A decision analysis model was also constructed to simulate the CRC screening process biennially and annually, as close to reality as possible, by taking into consideration factors mentioned above. The direct medical cost was calculated using government data. The current colonoscopy capacity in the city of London was then examined which provided important information about whether the current system would be equipped to handle the extra endoscopic procedures generated by the population-based screening.

\section{FP survey}

A faxed survey study was conducted to examine the current practice of CRC screening among FPs in London. The one-page survey was designed to investigate the current practice among FPs in using the FOBT for CRC screening, the patients' response and the FPs' choice of investigation modalities after a positive screening result. Contact information for FPs located in London was obtained from the College of Physicians and Surgeons of Ontario (Web site < www.cpso.on.ca>). A total of 135 surveys were faxed to the FP clinics. Results were applied to a decision model in calculating the future colonoscopy requirement for a populationbased CRC screening in London.

\section{Decision analysis model}

A decision analysis model was developed to simulate the steps involved in biennial and annual population-based CRC screening in London. The model was applied to calculate the number of consultations, colonoscopies and polypectomies generated by the screening program between 2006 and 2015. Although the current Health Canada guidelines suggest biennial FOBTs for CRC screening, the number of colonoscopies generated from both the biennial and annual screening protocols was calculated. The estimated number of eligible candidates, between 50 and 74 years of age, in different years, as well as the death rate within this age group, was based on the population projection data provided by the Department of Planning and Development.

The biennial decision model consists of one arm for 2006/2007 (Figure 1A [18]) and three arms for 2008 to 2015 (Figure 1B), due to the different prevalence rate for first-time screening and rescreening. Each box represents one decision step. Assumptions were made to each step based on prevalence rates from the FP surveys (Table 1 ) or randomized studies, as outlined in Table 2 . This model was also applied to annual screening, assuming the same prevalence rates in annual and biennial screening. The corresponding direct medical costs for the consultation services, colonoscopies and polypectomies were calculated using data from the government source.

\section{Current colonoscopy capacity and indications for colonoscopies}

To study the current colonoscopy capacity in London, the total number of outpatient colonoscopies performed in the three hospitals (St Joseph's Health Care, University Hospital and Victoria Hospital) during 2003 was examined. Among the outpatient colonoscopies performed in Victoria Hospital within this period, 123 charts were randomly retrieved and reviewed to investigate the indication for colonoscopies.

\section{Sensitivity analysis}

All of the probabilities used in the present analysis were subjected to a two-way sensitivity analysis in which the probability was varied across a plausible range to assess the impact on the result.

\section{FP survey}

\section{RESULTS}

A total of 135 surveys were faxed to the FP clinics. Of these, 39 completed surveys were received at the end of the two-week study period, for a response rate of $29 \%$. Results of the surveys (Table 1) were used as base case values in some of the decision steps in the model, as outlined in Table 2, including the percentage of FPs who offered FOBTs as CRC screening, the percentage of eligible population being offered FOBTs by FPs, the 


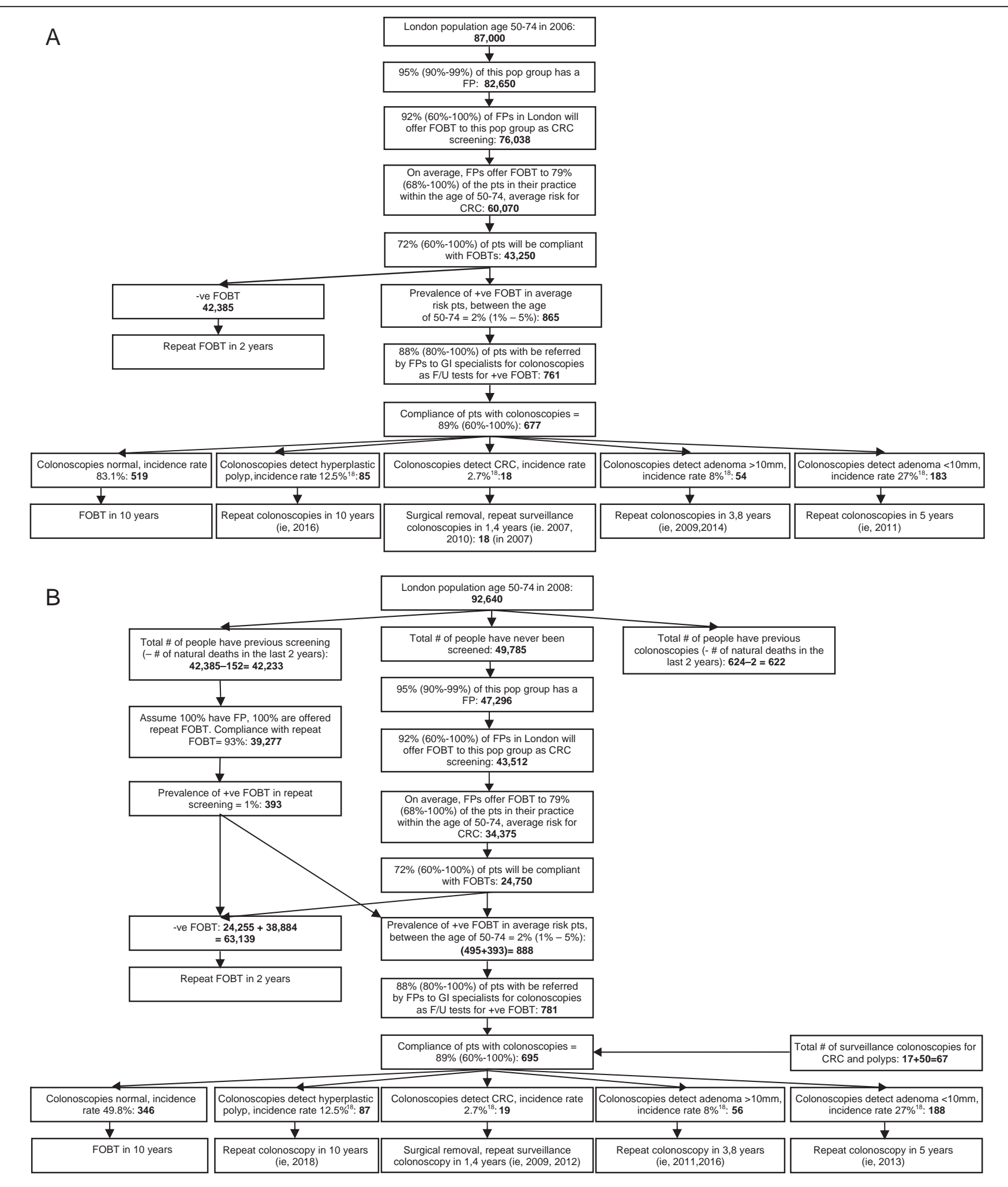

Figure 1) Decision model for colorectal cancer (CRC) screening in London, Ontario, 2006/2007 (A) and 2008/2009 (B). The decision models for the years 2010 to 2015 were identical to the model for 2008/2009 using a biennial screening approach, with the same prevalence rate for each decision step. The same model was applied to annual screening, assuming the same prevalence rate as in biennial screening. Each box represents one decision step in the model. The number in percentage represents the case base value used in each decision step, based on the prevalence rate from the family physician (FP) survey (Table 1) or the randomized studies as listed in Table 2. The numbers in parentheses represent the plausible range of the case base value used in the two-way sensitivity analysis (Table 2). The final calculated number of consultations and endoscopic procedures is listed in Table 3 . The frequency of repeat surveillance colonoscopies after the diagnosis of CRC or adenoma was based on the recommendations from the 2006 guidelines published by the American Cancer Society and the American Gastroenterology Association (17), with some modifications to simplify calculations in the model. -ve Negative; \# Number; +ve Positive; F/U Follow-up; FOBT Fecal occult blood test; GI Gastroenterology; Pop Population; pts Patients 
TABLE 1

Summary of family physician (FP) colorectal cancer (CRC) screening survey

\begin{tabular}{lcc}
\hline & \multicolumn{2}{c}{ FPs' response } \\
\cline { 2 - 3 } & $\%$ & Mean $\%$ \\
\hline Were patients offered FOBTs & & \\
for CRC screening? $(\mathrm{n}=39)$ & & - \\
$\quad$ Yes & 92.3 & - \\
$\quad$ No & 7.7 & 67.8 \\
Eligible patients offered FOBTs $(\mathrm{n}=36)$ & - & 71.9 \\
Eligible patients accepted FOBTs $(\mathrm{n}=36)$ & - & 79.0 \\
In 2006, eligible patients anticipated to be & - & - \\
offered FOBTs ( $\mathrm{n}=39)$ & & - \\
Preferred investigation after a positive FOBT $(\mathrm{n}=37)$ & & - \\
Specialist referral & 16.2 & - \\
Colonoscopy & 62.2 & - \\
Flexible sigmoidoscopy & 2.7 & - \\
Barium enema & 16.2 & \\
Repeat FOBT & 2.7 & \\
\hline
\end{tabular}

FOBTs Fecal occult blood tests

percentage of patients' compliance with FOBTs and the percentage of FPs who offered colonoscopy as follow-up testing after a positive FOBT.

Estimated number of consultations, endoscopic procedures and corresponding direct medical costs from decision models

In applying the decision analysis model which simulated a population-based biennial and annual CRC screening program in London between 2006 and 2015 (Figures 1A,B), an extra 381 to 445 consultations, 339 to 396 screening colonoscopies and nine to 176 surveillance colonoscopies generated by the initial screening procedures, and 161 to 188 polypectomies generated per year from the biennial screening were estimated which approximately doubled in numbers in annual screening (Table 3). In other words, for every 100,000 screen eligible population per year, 396 to 438 consultations, 387 to 522 colonoscopies and 167 to 185 polypectomies will be required from biennial CRC screening, and approximately double these numbers in the case of annual screening. Using data from the Ontario Health Insurance Plan billing system, it is estimated that a total of $\$ 2.8$ million or $\$ 5.6$ million will be required in the coming 10 years to support the extra consultation and endoscopic procedures generated by the biennial or annual population-based CRC screening program in London (Table 4). There is a trend toward increasing number of consultations and procedures required over the years, likely reflecting the aging population and the earlier detection of CRC and adenoma by the screening program.

\section{Extra demand on current colonoscopy capacity}

To evaluate whether the current health care system in London can accommodate the extra endoscopic procedures generated by the population-based screening program, the current colonoscopy capacity of the city of London was examined. During the year 2003, 5273 outpatient colonoscopies were performed in the three hospitals in London, of which approximately $2 \%$ were performed as follow-up investigations for positive FOBTs (Table 5). Therefore, based on the model, a
$6.6 \%$ to $10.8 \%$, or $12.8 \%$ to $22.3 \%$ increase per year is anticipated in outpatient colonoscopies generated by the biennial or annual screening, respectively, compared with 2003 (Figure 2A). The percentage of outpatient colonoscopies as follow-up investigations for positive FOBTs will increase from $2.0 \%$ to $6.0 \%$ to $6.8 \%$ per year in biennial screening or $11.4 \%$ to $12.8 \%$ per year in annual screening (Figure 2B).

\section{Sensitivity analysis}

Most of the base case values used in the decision model were based on the FP survey results and randomized studies. These values may be subject to significant variability leading to a significant impact on the final calculation. Sensitivity analysis was performed to take into account the variability of the base case values and to examine their impact on the final estimated number of colonoscopies. The ranges for the sensitivity analysis were selected mostly based on results from randomized studies. These ranges and their effect on the estimated number of colonoscopies, either individually or in combination with others variables, are listed in Table 2. Among all of the variables, the estimated number of colonoscopies was most sensitive to the change in prevalence of positive FOBTs during the initial screening. This was mainly a result of the small numerical value of the prevalence compared with other variables, as well as its comparatively wider range.

\section{DISCUSSION}

CRC is a very common disease found in developed countries. A recent study (9) showed that the incidence of CRC in Ontario was among the highest in the world, along with New Zealand, the United States and several European countries. According to the "Canadian Cancer Statistics 2006" (1), one in 13.7 men (lifetime probability of $7.3 \%$ ) and one in 15.7 women (lifetime probability of $6.4 \%$ ) will develop CRC during their lifetimes. One in 28.4 men (lifetime probability of $3.5 \%$ ) and one in 30.6 women (lifetime probability of $3.3 \%$ ) will die from the disease (1). Between 1981 and 2001, CRC mortality had been declining, likely because of favourable dietary changes and the increased use of colonoscopies for screening and diagnosis. Despite the declining incidence of and mortality rates for CRC, the absolute numbers of new cases and deaths from CRC will continue to rise to 2010, according to the projection data, due to the aging 'baby boomer' generation (13).

The POHEM is a "microsimulation tool developed by Statistics Canada to model various aspects of the health of Canadians and to evaluate possible interventions" $(14,15)$. The Canadian CRC model of incidence and progression was incorporated into the POHEM in 2000 to simulate a population-based CRC screening program. When developing the screening model, most of the parameters were based on data from the Funen trial, and some other trials when appropriate. With an assumed participation rate of $67 \%$ in the population between 50 and 74 years of age, the biennial screening would result in an estimated 10-year CRC mortality reduction of $16.7 \%$ in 2000 . The life expectancy of the cohort would increase by 15 days on average. The total number of colonoscopies generated by the screening program per year would be 55,845 in 2000 for Canada and 17,776 for Ontario. This would reflect a $15 \%$ increase in demand for colonoscopies in the first year of screening.

In comparison, our model estimated only a $6.6 \%$ increase in colonoscopy demand in London during the first year of biennial 
TABLE 2

Base case values and sensitivity analysis (biennial screening)

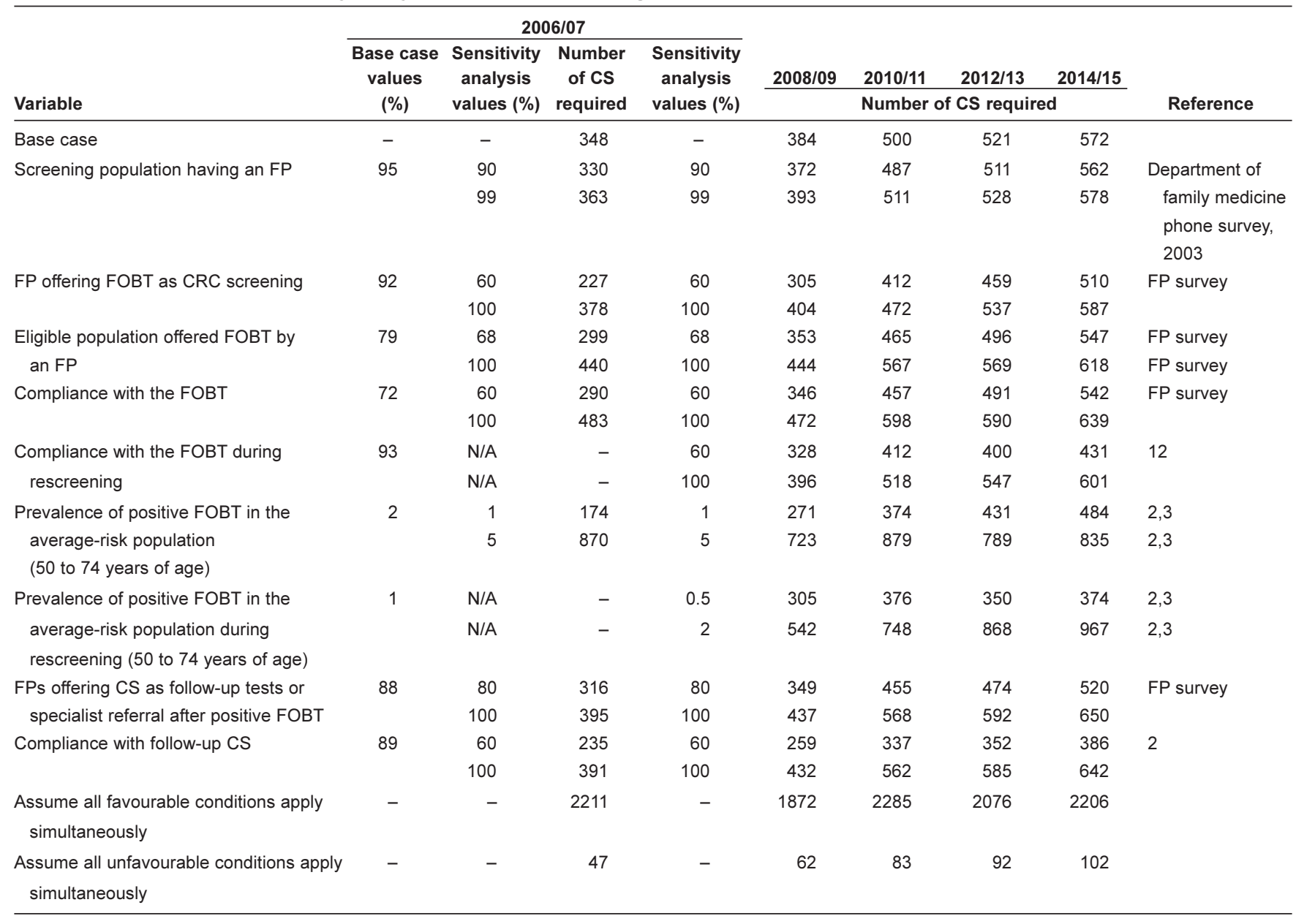

CRC Colorectal cancer; CS Colonoscopy; FOBT Fecal occult blood test; FP Family physician; N/A Not applicable

TABLE 3

Estimated number of consultations, colonoscopies (CS) and polypectomies generated by annual and biennial colorectal cancer screening

\begin{tabular}{|c|c|c|c|c|c|c|c|c|c|c|c|c|}
\hline \multirow[b]{3}{*}{ Year } & \multicolumn{2}{|c|}{ Population } & \multirow{2}{*}{\multicolumn{2}{|c|}{ Consultation ${ }^{*}, \mathrm{n}$}} & \multirow{2}{*}{\multicolumn{2}{|c|}{ Screening CS $^{*}, \mathbf{n}$}} & \multirow{2}{*}{\multicolumn{2}{|c|}{ Surveillance $\mathbf{C S}^{*}, \mathrm{n}$}} & \multirow{2}{*}{\multicolumn{2}{|c|}{ Total $\mathrm{CS}^{*}, \mathrm{n}$}} & \multirow{2}{*}{\multicolumn{2}{|c|}{ Polypectomy*, n }} \\
\hline & \multirow{2}{*}{$\begin{array}{l}\text { All age } \\
\text { groups, } n\end{array}$} & \multirow{2}{*}{$\begin{array}{l}50-74 \text { year } \\
\text { age group, } n\end{array}$} & & & & & & & & & & \\
\hline & & & Annual & Biennial & Annual & $\overline{\text { Biennial }}$ & Annual & $\overline{\text { Biennial }}$ & Annual & $\overline{\text { Biennial }}$ & Annual & Biennial \\
\hline Total & Cohort 0 & 0.14 million & 8168 & 4097 & 7367 & 3646 & 1731 & 1004 & 9098 & 4650 & 3500 & 1732 \\
\hline 2006 & 355,900 & 87,000 & $761(875)$ & 381 (438) & $677(779)$ & $339(390)$ & $0(0)$ & $9(10)$ & 677 (779) & $348(400)$ & $322(370)$ & 161 (185) \\
\hline 2007 & 359,540 & 89,820 & $756(842)$ & 381 (424) & $673(749)$ & 339 (377) & $18(20)$ & $9(10)$ & 691 (769) & $348(387)$ & $320(356)$ & 161 (179) \\
\hline 2008 & 363,180 & 92,640 & $770(831)$ & 391 (422) & $685(740)$ & $348(376)$ & $18(19)$ & $36(39)$ & 703 (759) & $384(415)$ & $325(351)$ & 165 (178) \\
\hline 2011 & 374,100 & 101,100 & $833(824)$ & $407(403)$ & $741(733)$ & $362(358)$ & $275(272)$ & $138(136)$ & $1016(1005)$ & $500(495)$ & $352(348)$ & $172(170)$ \\
\hline 2012 & 377,740 & 103,920 & $855(823)$ & 425 (409) & $761(733)$ & $378(364)$ & $276(266)$ & $143(138)$ & 1037 (998) & $521(501)$ & $362(348)$ & 180 (173) \\
\hline 2013 & 381,380 & 106,740 & $878(823)$ & $425(398)$ & $782(732)$ & $378(354)$ & $283(265)$ & $143(134)$ & 1065 (998) & $521(488)$ & $371(348)$ & 180 (169) \\
\hline 2014 & 385,020 & 109,560 & $901(823)$ & $445(406)$ & $802(732)$ & $396(361)$ & $346(316)$ & $176(161)$ & $1148(1048)$ & $572(522)$ & $381(348)$ & $188(172)$ \\
\hline 2015 & 388,660 & 112,380 & $925(823)$ & $445(396)$ & $823(732)$ & $396(352)$ & $352(313)$ & $176(157)$ & $1175(1045)$ & $572(509)$ & $391(348)$ & $188(167)$ \\
\hline
\end{tabular}

*Per 100,000 population

screening. When applying the eligible screening population, a cohort of 140,000 people in the POHEM, between 2006 and 2015, the estimated number of colonoscopies per year from biennial and annual screening would be 1117 and 2233, respectively. The number generated from our model is approximately $58 \%$ of what was estimated from the POHEM. There are several factors contributing to this significant variance. First of all, the POHEM for CRC screening was mainly based 
TABLE 4

Estimated cost from consultations, colonoscopies and polypectomies generated by annual and biennial colorectal cancer screening in London, Ontario between 2006 and 2015

\begin{tabular}{|c|c|c|c|c|c|c|c|c|}
\hline \multirow[b]{2}{*}{ Year } & \multicolumn{2}{|c|}{ Consultation cost $(\$)^{*}$} & \multicolumn{2}{|c|}{ Colonoscopy cost $(\$)^{\dagger}$} & \multicolumn{2}{|c|}{ Polypectomy cost $(\$)^{\ddagger}$} & \multicolumn{2}{|c|}{ Total cost (\$) } \\
\hline & Annual & Biennial & Annual & Biennial & Annual & Biennial & Annual & Biennial \\
\hline 2006 & 94,136 & 47,117 & 297,880 & 153,120 & 55,706 & 27,853 & 447,722 & 228,090 \\
\hline 2007 & 93,517 & 47,117 & 304,040 & 153,120 & 55,360 & 27,853 & 452,917 & 228,090 \\
\hline 2008 & 81,642 & 48,368 & 309,320 & 168,960 & 56,225 & 28,545 & 447,187 & 245,873 \\
\hline 2009 & 97,599 & 48,368 & 340,560 & 168,960 & 57,609 & 28,545 & 495,768 & 245,873 \\
\hline 2010 & 100,197 & 50,314 & 357,280 & 220,000 & 59,339 & 29,756 & 516,816 & 300,070 \\
\hline 2011 & 103,042 & 50,314 & 447,040 & 220,000 & 60,896 & 29,756 & 610,978 & 300,070 \\
\hline 2012 & 105,764 & 52,538 & 456,280 & 229,240 & 62,626 & 31,140 & 624,670 & 312,918 \\
\hline 2013 & 108,609 & 52,538 & 468,600 & 229,240 & 64,183 & 31,140 & 641,392 & 312,918 \\
\hline 2014 & 111,454 & 55,040 & 505,120 & 251,680 & 65,913 & 32,524 & 682,487 & 339,244 \\
\hline 2015 & 114,423 & 55,040 & 517,000 & 251,680 & 67,643 & 32,524 & 699,066 & 339,244 \\
\hline Total & 101,382 & 506,753 & $4,003,120$ & $2,046,000$ & 605,500 & 299,636 & $5,619,002$ & $2,852,389$ \\
\hline
\end{tabular}

${ }^{*}$ Cost of consultation (per positive fecal occult blood test) $=\$ 123.70$, estimated from the Ontario Health Insurance Plan; ${ }^{\dagger}$ Cost of colonoscopy (per positive fecal occult blood test or follow-up to polyps) $=\$ 350.00$, estimated from day procedure group cost lists (Manitoba Health Services and Alberta Standard Cost List for Health Economics Evaluations) with estimates from Prince Edward Island by National Committee on Colorectal Cancer Screening member (12); ${ }^{\ddagger}$ Cost of polypectomy $=\$ 147.00$, estimated from day procedure group cost lists (Manitoba Health Services and Alberta Standard Cost List for Health Economics Evaluations) with estimates from Prince Edward Island by National Coordinating Council for Cancer Surveillance member (12)

TABLE 5

Indication for outpatient colonoscopy

\begin{tabular}{lc}
\hline Indication for colonoscopy & $\mathbf{n}(\%)^{*}$ \\
\hline Symptomatic & \\
Rectal bleeding & $19(15)$ \\
Abdominal pain & $17(14)$ \\
Change in bowel habits & $12(10)$ \\
Inflammatory bowel disease evaluation & $10(8)$ \\
Follow-up investigation after abnormal findings on barium enema & $6(5)$ \\
Anemia of unknown etiology & $6(5)$ \\
Weight loss & $2(2)$ \\
Asymptomatic & \\
Positive fecal occult blood test & $2(2)$ \\
Average-risk screening & $14(11)$ \\
High-risk screening & $20(16)$ \\
Personal history of polyps & $20(16)$ \\
Personal history of colorectal cancer & $10(8)$ \\
BRCA-1 mutation & $2(2)$ \\
Total number of patients & 123 \\
\hline
\end{tabular}

${ }^{*}$ Total is greater than $100 \%$ because some patients had more than one indication for colonoscopy

on the Funen trial, a randomized controlled trial performed in Denmark. In such a controlled setting, the participation rate of $67 \%$ was achieved based on the assumption that aggressive recruitment would be involved, including media promotion, letters of invitation and visits to FPs. Our model was premised on a more realistic approach, based on the current situation in London. Though the participation rate of the candidates was $72 \%$, according to the FP survey, only $50 \%$ of them would finally have FOBTs because of other factors which would decrease the overall participation, including the accessibility to FPs (there are 23,000 people in London, in total, who do not have FPs) and the participation rate among the FPs. Moreover, in the POHEM, all people with positive FOBTs receive colonoscopies. In our model, because of the limitation to access gastroenterologists and colonoscopies, as well as

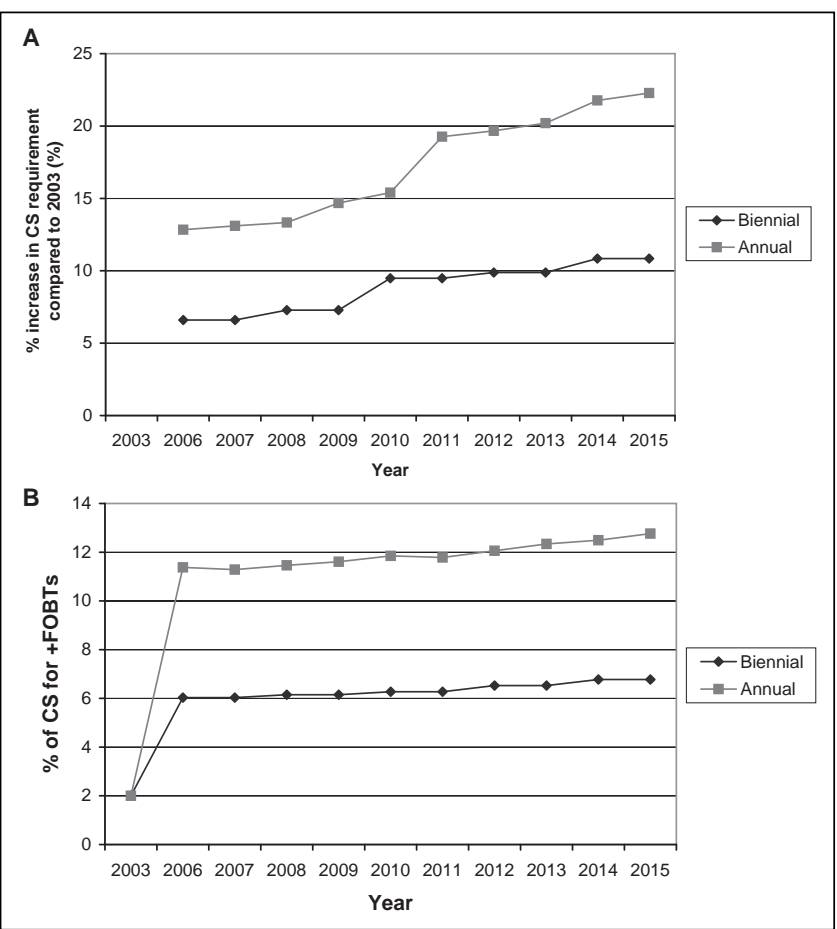

Figure 2) Percentage increase in colonoscopy (CS) requirement (A) and percentage of CS' as follow-up investigation for positive fecal occult blood tests (+FOBTs) per year (B) generated by the population-based biennial and annual colorectal cancer screening program

patient compliance, only $78 \%$ of those with positive FOBTs would end up having colonoscopies.

The FP survey is a significant limiting factor in our model. First, the response rate of the survey study was only 29\%, with a total of 39 surveys to review, which is a small sample size. There might have been a nonresponse bias and volunteer effect which would explain the high participation rate of 92\% among FPs who would offer FOBTs. According to an observational study conducted in 2001 and published in 2004 (16), only 60\% of FPs 
offered FOBT to average-risk patients for CRC screening, an increase from $43 \%$ after the Canadian Task Force on Preventive Health Care upgraded FOBTs to an 'A' recommendation for CRC screening.

CRC is a common disease among the elderly and carries a significant mortality rate. On the other hand, early CRC screening with FOBTs has been shown to cause a significant reduction in mortality rates. Colonoscopies have been shown to be the most sensitive and effective follow-up investigation method for CRC screening after a positive FOBT result. With the anticipation of increasing CRC cases and deaths in the coming 10 years due to the aging 'baby boomer' generation, as well as strong evidence that FOBTs as a CRC screening tool can decrease mortality, population-based CRC screening is a significant step toward improving the life-expectancy and the quality of life in the Canadian population. Significant economic resources will be required to handle the increased number of investigations and personnel involved in the screening program. Using the city of London as a model with a cohort population of 140,000 , a total of $\$ 2.8$ million or $\$ 5.6$ million will be required to support the direct medical cost generated by the extra consultations and endoscopic procedures from the biennial or annual screening program in the coming 10 years. Based on data from Statistics Canada, the total population of the city of London in 2006 was approximately 356,000,

\section{REFERENCES}

1. Canadian Cancer Society. Canadian Cancer Statistics 2006. <http://129.33.170.32/vgn/images/portal/cit_86751114/31/21/9355 05792cw_2006stats_en.pdf.pdf $>$ (Version current at January 23, 2007).

2. Kronborg O, Fenger C, Olsen J, Jorgensen OD, Sondergaard O. Randomised study of screening for colorectal cancer with faecal-occult-blood test. Lancet 1996;348:1467-71.

3. Hardcastle JD, Chamberlain JO, Robinson MH, et al. Randomised controlled trial of faecal-occult-blood screening for colorectal cancer. Lancet 1996;348:1472-7.

4. Mandel JS, Bond JH, Church TR, et al. Reducing mortality from colorectal cancer by screening for fecal occult blood. Minnesota Colon Cancer Control Study. N Engl J Med 1993;328:1365-71. (Erratum in 1993;329:672).

5. National Committee on Colorectal Cancer Screening, Health Canada. Recommendations for population-based colorectal cancer screening. <http://www.phac-aspc.gc.ca/ publicat/ncccs-cndcc/ccsrec_e.html $>$ (Version current at January 23, 2007).

6. Canadian Task Force on Preventive Health Care. Colorectal cancer screening. Recommendation statement from the Canadian Task Force on Preventive Health Care. CMAJ 2001;165:206-8.

7. Rabeneck L, Paszat LF. A population-based estimate of the extent of colorectal cancer screening in Ontario. Am J Gastroenterol 2004;99:1141-4.

8. Cancer Care Ontario. Targeting cancer - an action plan for cancer prevention and detection. Cancer 2020 Background Report. <http://cancercare.on.ca/documents/ Cancer2020BackgroundReportMay2003.pdf> (Version current at January 23, 2007).

9. Cancer Care Ontario. Insight on cancer - news and information on colorectal cancer. < http://www.cancer.ca/vgn/ approximately $1.1 \%$ of the total Canadian population $(32,547,000)(1)$. The extrapolated direct medical cost for a nationwide population-based CRC screening will be approximately $\$ 255$ million for biennial screening or \$509 million for annual screening in the coming 10 years.

\section{SUMMARY}

Our analysis indicates that widespread acceptance of FOBT screening by FPs will lead to increased utilization of endoscopic resources and increased upfront costs. However, it is clear that this increase is well within the present means of the system if appropriate dollars are allocated, at least for the biennial screening. It is hoped that such efforts will lead not only to decreased future medical expenditures for the treatment of advanced CRC but also to the increased future productivity of those individuals spared from this tragic, yet for the most part preventable, disease.

ACKNOWLEDGEMENTS: The authors would like to thank Dr Tom Freeman, Chair of the Department of Family Medicine at the University of Western Ontario (London, Ontario), for sharing his preliminary data from a telephone survey study regarding the shortage of family physicians in London. Also thanked is the Department of Planning and Development for sharing the population projection data of the city of London. images/portal/cit_86751114/22/13/185530396niw_od_ioc_colorect al.pdf $>$ (Version current at January 23, 2007).

10. Winawer S, Fletcher R, Rex D, et al. Colorectal cancer screening and surveillance: Clinical guidelines and rationale - update based on new evidence. Gastroenterology 2003;124:544-60.

11. McGrath JS, Ponich TP, Gregor JC. Screening for colorectal cancer: The cost to find an advance adenoma. Am J Gastroenterol 2002;97:2902-7.

12. Flanagan WM, Le Petit C, Berthelot JM, White KJ, Coombs BA, Jones-McLean E. Potential impact of population-based colorectal cancer screening in Canada. Chronic Dis Can 2003;24:81-8.

13. Waters C, Huchcroft SA, Mao Y, et al. Colorectal cancer in Canada to the year 2010. Cancer Strategy 2000;2:76-80.

14. Wolfson MC. POHEM - a framework for understanding and modelling the health of human populations. World Health Stat Q 1994:47:157-76.

15. Berthelot J-M, Le Petit C, Flanagan W. Use of longitudinal data in health policy simulation models. Proceedings of the Section on Government Statistics and Section on Social Statistics. American Statistical Association, 1997:120-9.

16. Asano TK, Toma D, Stern HS, McLeod RS. Current awareness in Canada of clinical practice guidelines for colorectal cancer screening. Can J Surg 2004;47:104-8.

17. Winawer SJ, Zauber AG, Fletcher RH, et al. Guidelines for colonoscopy surveillance after polypectomy: A consensus update by the US Multi-Society Task Force on Colorectal Cancer and the American Cancer Society. CA Cancer J Clin 2006;56:143-59.

18. Lieberman DA, Weiss DG, Bond JH, Ahnen DJ, Garewal H, Chejfec G. Use of colonoscopy to screen asymptomatic adults for colorectal cancer. Veterans Affairs Cooperative Study Group 380. N Engl J Med 2000;343:162-8. (Erratum in 2000;343:1204). 


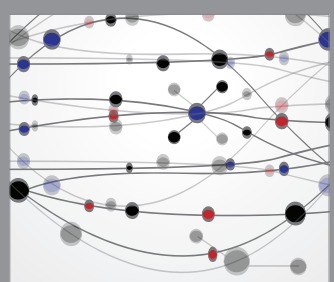

The Scientific World Journal
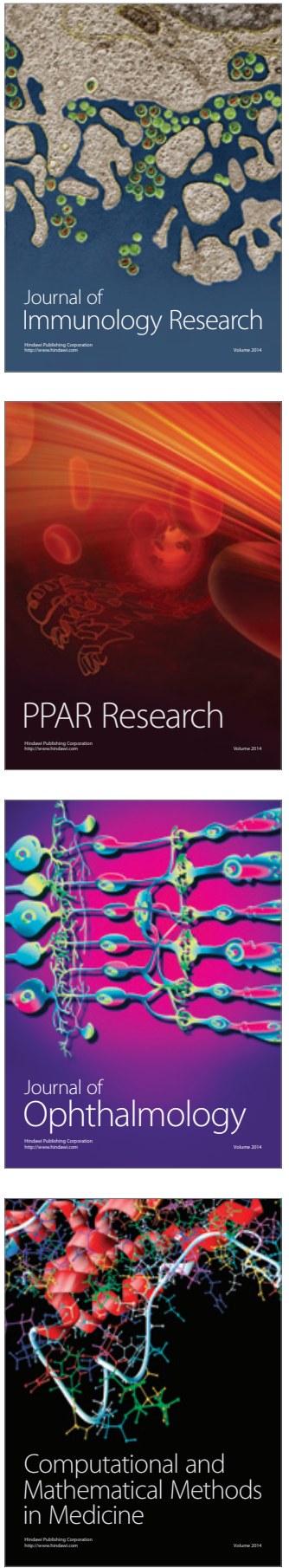

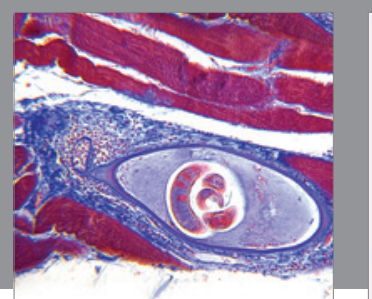

Gastroenterology Research and Practice

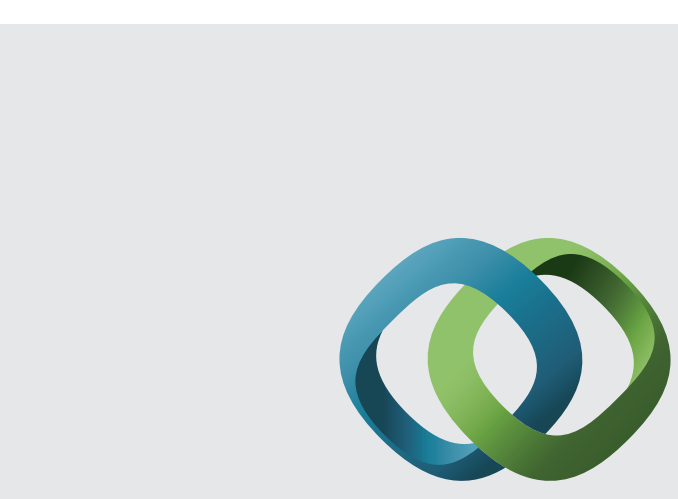

\section{Hindawi}

Submit your manuscripts at

http://www.hindawi.com
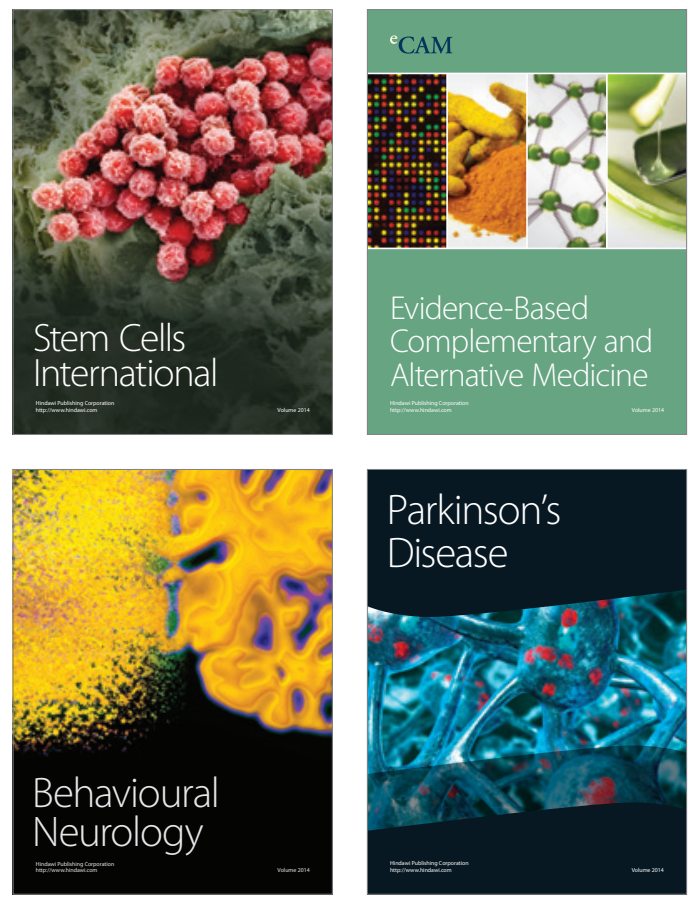
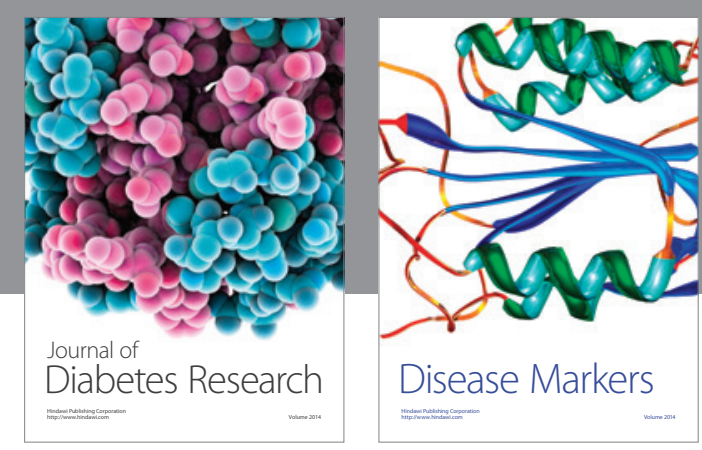

Disease Markers
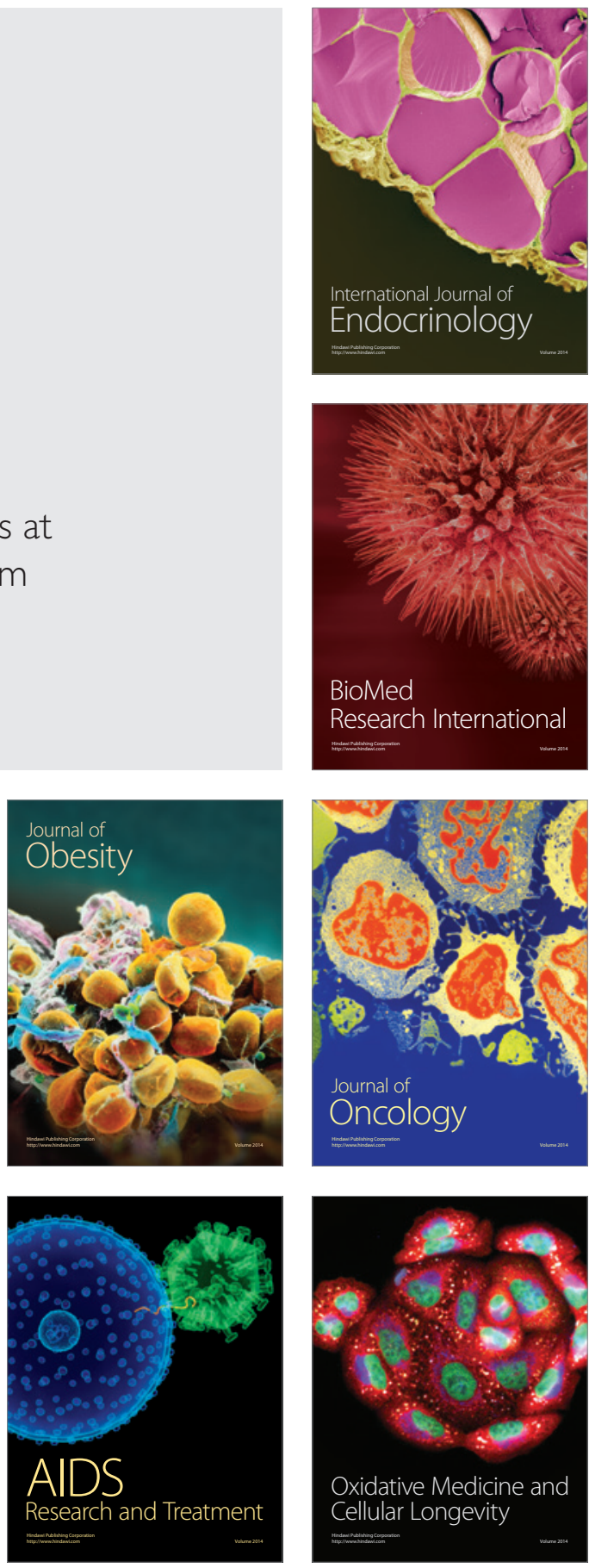